\title{
Mirroring Display KWH Meter untuk Memantau Penggunaan Daya Listrik Menggunakan Mikrokontroler ESP32-CAM
}

\section{Mirroring the KWH Meter Display to Monitor Electric Power Consumption Using the ESP32-CAM Microcontroller}

\author{
Ilham Dwi Christanto ${ }^{1}$, Reza Diharja ${ }^{2 *}$, Mardiono ${ }^{3}$, Parama Diptya Widayaka ${ }^{4}$, Alfarid Hendro \\ Yuwono ${ }^{5}$ \\ 1,2,3 Teknik Elektro, Universitas Jayabaya \\ ${ }^{4}$ Teknik Elektro, Universitas Negeri Surabaya \\ ${ }^{5}$ Teknik Elektro, Institut Teknologi Nasional Malang \\ reza.diharja@jayabaya.ac.id ${ }^{2 *}$
}

Submitted: 14 Desember 2021, Revised: 19 Desember 2021, Accepted: 21 Desember 2021

\begin{abstract}
Abstrak - Alat "Mirroring Display KWH Meter untuk Memantau Penggunaan Daya Listrik Menggunakan Mikrokontroler ESP32-CAM" telah berhasil dibuat. Dasar pembuatan alat karena petugas PLN pencatat $\mathrm{kWh}$ meter tidak dapat masuk ke rumah sehingga perhitungan pemakaian listrik bulanan disamaratakan dengan pemakaian listrik pada bulan sebelumnya dan pelanggan dapat dirugikan. Pada alat terdapat sebuah layar memperlihatkan nilai pemakaian daya setiap bulannya yang penerapannya dapat ditempatkan di luar rumah. Alat dilengkapi dengan teknologi IoT sehingga pemakaian daya dapat dipantau dari jarak jauh. Dari hasil pengujian dan pengukuran, didapatkan informasi semakin besar nilai beban yang diterapkan pada aliran listrik, akan berefek pada nilai data seperti arus dan tegangan. Data yang didapatkan dari modul sensor PZEM-004T masih harus dilakukan penyesuaian agar mendekati nilai sebenarnya. Nilai rasio VA hasil pengukuran melalui modul sensor PZEM-004T dan alat ukur multimeter adalah 99,12\% untuk satu beban dan 96,97\% untuk dua beban. Hasil tersebut dapat digunakan untuk pemantauan pemakaian daya tiap bulannya menggunakan alat ukur yang berbeda. Kedepannya, proses mirroring display dapat diterapkan pada aplikasi Android di gawai sehingga dapat memudahkan pengguna.
\end{abstract}

Kata Kunci: daya, IoT, kWh meter, mirroring display, rasio VA

\begin{abstract}
The "KWH Meter Mirroring Display Tool to Monitor Electrical Power Use Using ESP32CAM Microcontrollers" has been successfully completed. The main reason for its creation was that PLN officers who register $k W h$ meters were unable to enter the house. As a result, the calculation of monthly electricity usage is not equalized with electricity usage in the previous month, and customers are dissatisfied. On the device, there is a screen that displays the monthly value of power usage, and the implementation can be placed outside of the house. The tool is equipped with IoT technology, allowing for remote monitoring of power consumption. According to the outcomes of testing and measurements, the greater the load value applied to the electricity flow, the greater the effect on data values such as current and voltage. The data obtained from the PZEM-004T sensor module must still be adjusted to get close to its true value. The VA ratio value of measurement results obtained using the PZEM-004T sensor module and multimeter gauge is $99.12 \%$ for a single load and $96.97 \%$ for two loads. These results can be used to track power usage each month with a different measurement device. The mirroring display process can be applied to android applications on the smartphone in the future to help users.
\end{abstract}

Keywords: loads, power, $k$ Wh meter, mirroring display, VA ratio.

Jurnal Bumigora Information Technology (BITe)

Vol.3, No.2, Desember 2021, pp. 161-174

ISSN: $2685-4066$

DOI: $10.30812 /$ bite.v3i2.1613 


\section{Pendahuluan}

Energi listrik sudah menjadi kebutuhan bagi manusia khususnya jika tinggal di wilayah perkotaan. Banyak peralatan perkakas rumah tangga yang hanya dapat digerakkan atau digunakan hanya dengan menggunakan energi listrik. Selain digunakan untuk keperluan utama seperti mencuci pakaian dan memasak, energi listrik juga digunakan untuk penerangan, hiburan dll. Manusia perlu memantau penggunaan energi listrik agar efektif dan efisien demi menjaga ketersedian listrik bagi pengguna lainnya karena dari tahun ke tahun, kebutuhan akan hal ini semakin membesar [1].

Penggunaan peralatan listrik tentunya berkaitan langsung dengan pengukuran daya listrik. Daya listrik dapat diartikan sebagai banyaknya penggunaan energi yang diterapkan pada alat atau benda per satuan waktu. Listrik PLN terdiri dari dua komponen daya yakni daya aktif dan reaktif. Sedangkan daya yang digunakan pada peralatan elektronik merupakan daya aktif [1]. Untuk memantau penggunaan daya listrik, dibutuhkan komponen nilai arus dan tegangan yang terpakai oleh peralatan listrik. Agar seseorang dapat mengetahui konsumsi daya listrik yang terpakai, dibutuhkan perantara alat ukur. Akan tetapi untuk mengetahui besarnya daya listrik yang terpakai di rumah-rumah masih harus dicek dan dicatat oleh petugas secara manual dan belum bisa dilakukan pemantauan dari jarak jauh.

Cara yang dilakukan oleh PLN dalam mengumpulkan informasi penggunaan energi listrik yang tercatat pada KWh meter adalah dengan mendatangkan petugas lapangan yang mencatat langsung penggunaan energi listrik per bulannya secara manual [2]. Ketika terdapat KWh meter yang tidak terjangkau petugas, penyedia energi listrik menyimpulkan dan menarik nilai rata-rata penggunaan energi listrik harian pada bulan sebelumnya. Hal tersebut sangat berdampak kepada konsumen bahwa tagihan listrik bulanannya bisa saja lebih tinggi dari biasanya.

Permasalahan tersebut menjadi ihwal pemikiran bahwa perlu ada alat yang dapat digunakan sebagai wahana pemantauan dan penampil nilai KWh meter secara realtime. Saat ini monitoring besaran listrik seperti tegangan, arus, daya, dan faktor daya banyak dilakukan dengan cara memasang alat ukur listrik di panel listrik sebelum masuk ke beban. Cara ini memiliki kekurangan yaitu konsumen harus berada di lokasi alat ukur tersebut sehingga tidak efisien karena tidak dapat langsung diketahui secara realtime.

Ide yang telah eksis saat ini adalah menggunakan sensor PZEM004T sebagai alat bantu ukur tegangan dan arus listrik, dapat ditempatkan di mana saja sesuai dengan keperluan. Penelitian yang dilakukan oleh Risfendra dkk menggunakan sensor PZEM004T dan mikrokontroler ESP8266 untuk memantau penggunaan energi pada peralatan listrik dari jarak jauh [3] . Penelitian yang dilakukan oleh Raviki Dwi Alfian dkk menerapkan sensor PZEM004T sebagai alat bantu ukur penggunaan energi listrik pada kamar kos [4]. Penelitian yang dilakukan oleh Andriana dkk yakni membuat sistem KWh meter digital berbasis sensor PZEM004T yang mana menggunakan tampilan LCD 16x2 dan aplikasi Blynk sebagai antarmuka untuk nilai tegangan dan arus yang terukur [5]. Sedangkan penelitian yang dilakukan oleh Syahrul Mustafa dan Umar Muhammad sudah membuat aplikasi berbasis Android namun tidak dilengkapi dengan tampilan pada LCD [2].

Saat ini, dengan kehadiran internet, sangat memungkinkan untuk melakukan pekerjaan pemantauan dari jarak jauh, tidak terkecuali pemantauan penggunaan energi listrik sudah banyak diterapkan. Melangkah lebih jauh pada penarapan internet, yakni Internet of Things (IoT) yang memungkinkan manusia melakukan pekerjaan secara remote, tidak terbatas ruang dan waktu. Ide ini dimulai dari konsep M2M atau machine to machine tentang bagaimana suatu perangkat atau sistem dapat terhubung dan bekomunikasi satu sama lainnya dengan menggunakan perantara kabel maupun nirkabel. Teknologi IoT merupakan sebuah jaringan besar yang terdiri dari banyak objek yang terhubung satu sama lain, khususnya hubungan antar sensor dan aktuator [6][1]. Sensor digunakan sebagai pengindera dan things dianggap sebagai aktuatornya. Melalui jaringan IoT, data dapat diakusisi, dikumpulkan, dipertukarkan hingga dianalisis untuk kemudian menghasilkan sebuah bentuk informasi yang utuh. 
Penerapan IoT diharapkan dapat meningkatkan efisiensi waktu, tenaga dan memberikan rasa aman dan nyaman kepada pengguna. Dari paparan bebagai macam permacalah di atas, tercetus ide membuat sebuah sistem yang dapat digunakan untuk pemantauan penggunaan daya listrik dan penampil (mirroring display) angka pada $\mathrm{kWh}$ meter berbasis IoT menggunakan mikrokontroler ESP 32 CAM.

\section{Metode Penelitian}

Metode penelitian menjabarkan komponen-komponen yang berkaitan langsung dengan sistem yang dibuat. Selain itu terdapat pula blok diagram dan diagram alir penelitian khusunya pada pembuatan sistem elektronik dan aplikasi.

\subsection{Tinjauan Pustaka}

\subsubsection{Modul ESP 32 CAM}

ESP32-CAM memiliki modul kamera dengan dimensi 27 x 40,5 x 4,5mm, kompak, dapat beroperasi secara sendiri dengan sistem minimum. Konsumsi arus hingga $6 \mathrm{~mA}$, menjadikan ESP 32-CAM dapat digunakan secara luas di berbagai aplikasi IoT. Dapat diaplikasikan pada bidang IoT seperti rumah pintar, pengendali di industri secara nirkabel, pemantauan secara nirkabel, identifikasi secara nirkabel berbasis QR, sinyal system, penentuan posisi secara nirkabel dan aplikasi IoT lainnya. ESP32-CAM mengadopsi paket DIP dan dapat langsung dimasukkan ke dalam backplane untuk dikoneksikan dengan perangkat keras yang lain secara cepat dan keandalan tinggi. ESP 32-CAM tidak memiliki antarmuka USB ke serial sehingga pemrograman harus dilakukan melalui antarmuka eksternal seperti USB to serial FTDI [7].

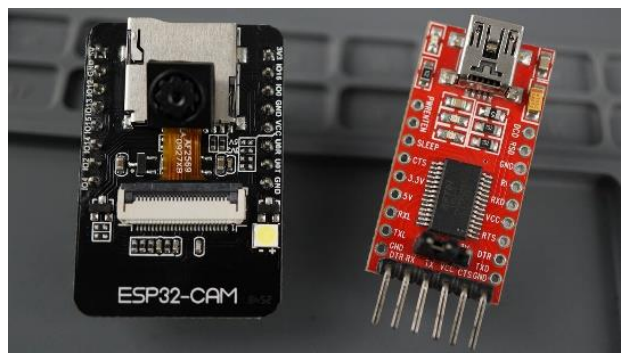

Gambar 1. Modul ESP32-CAM [8]

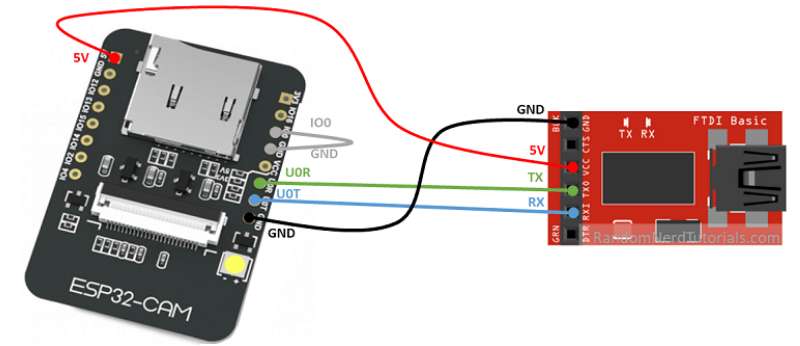

Gambar 2. Modul ESP-32 dengan USB to Serial FTDI [8]

\subsubsection{Modul Sensor PZEM004T Split core}

Modul PZEM004T merupakan sebuah modul sensor arus dan tegangan terintegrasi yang mampu mengukur daya, tegangan dan energi pada aliran listrik. Pada penerapannya, modul ini digunakan khusus untuk penggunaan dalam ruangan (indoor) dan beban yang terpasang tidak melibihi kemampuan daya yang dapat ditransfer kepadanya. Modul sensor PZEM-004T 100 Ampere menggunakan current transformer model split core yang memiliki keunggulan yakni dapat langsung dipasang pada kabel jaringan listrik yang sudah terpasang tanpa harus melepas kabel listrik tersebut. 


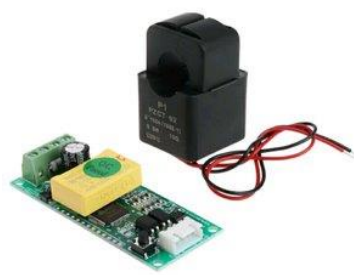

Gambar 3. Modul sensor PZEM-004T Split core

\subsubsection{AppInventor}

AppInventor merupakan aplikasi web opensource yang awalnya dikembangkan oleh Google, dan saat ini dikelola oleh Massachusetts Institute of Technology (MIT). AppInventor memungkinkan pengguna untuk menciptakan aplikasi perangkat lunak berbasis sistem operasi Android. AppInventor menggunakan antarmuka grafis yang berbasis visual block programming [9] yang memungkinkan pengguna men-drag dan drop objek visual saat proses pembuatan aplikasi dan tanpa perlu membuat kode apapun.

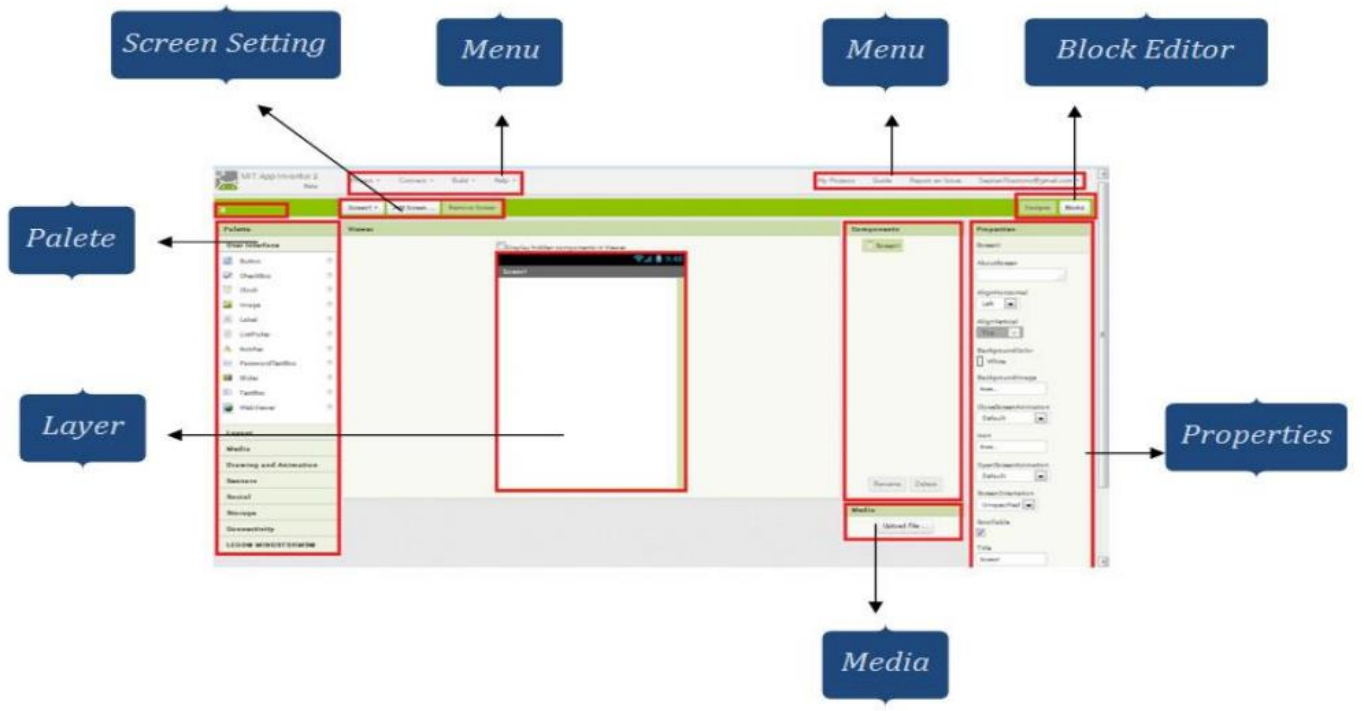

Gambar 4. Area kerja App Inventor

\subsubsection{Firebase}

Firebase merupakan framework yang sangat berguna untuk membangun aplikasi web portable yang ditujukan untuk keperluan bisnis. Hal tersebut tentunya membutuhkan database yang bersifat realtime sehingga ketika terdapat sesorang yang memperbarui pencatatan di database, maka pembaruan kemudian diteruskan kepada setiap pengguna lainnya secara instan [10]. Firebase memiliki produk utama yaitu menyediakan database realtime dan backend service. Layanan ini menyediakan pengembang aplikasi API yang memungkinkan aplikasi data yang akan disinkronisasi di klien dan disimpan di cloud Firebase. Library yang disediakan untuk client platform memungkinkan integrasi dengan Android, iOS, JavaScript, Java, Objective-C dan Node aplikasi Js dan dapat juga disebut sebagai layanan DbaaS (Database as a Service).

Pengembangan aplikasi berbasis Android yang menggunakan Firebase sangat membantu para pengembang untuk membuat aplikasi yang berkualitas tinggi dan dapat menumbuhkan basis pengguna yang interaktif. Berbagai fitur canggih dapat diterapkan pada aplikasi yang dibuat, seperti backend system, analisis, serta fitur pertumbuhan dan monetisasi. 


\subsection{Blok Diagram Sistem}

Blok diagram yang ditampilkan pada gambar 5 dijadikan sebagai acuan langkah-langkah yang dilakukan dalam penelitian. Blok diagram dibagi manjadi tiga bagian besar yaitu input, proses dan output. Modul mikrokontroler ESP 32 CAM dan sensor PZEM-004T digunakan sebagai wahana untuk mengakuisisi data. Selanjutnya, data berupa gambar mirroring display ditangkap oleh kamera yang diinstal padaa ESP 32 CAM. Selain itu, data dari modul sensor PZEM-004T diteruskan ke Arduino UNO agar dapat diolah menjadi informasi berupa nilai arus, tegangan dan daya. Aplikasi android yang dibangun dengan AppInventor bertujuan sebagai antarmuka utntuk menampilkan data realtime gambar dan besaran elektrik lainnya berbasis IoT.

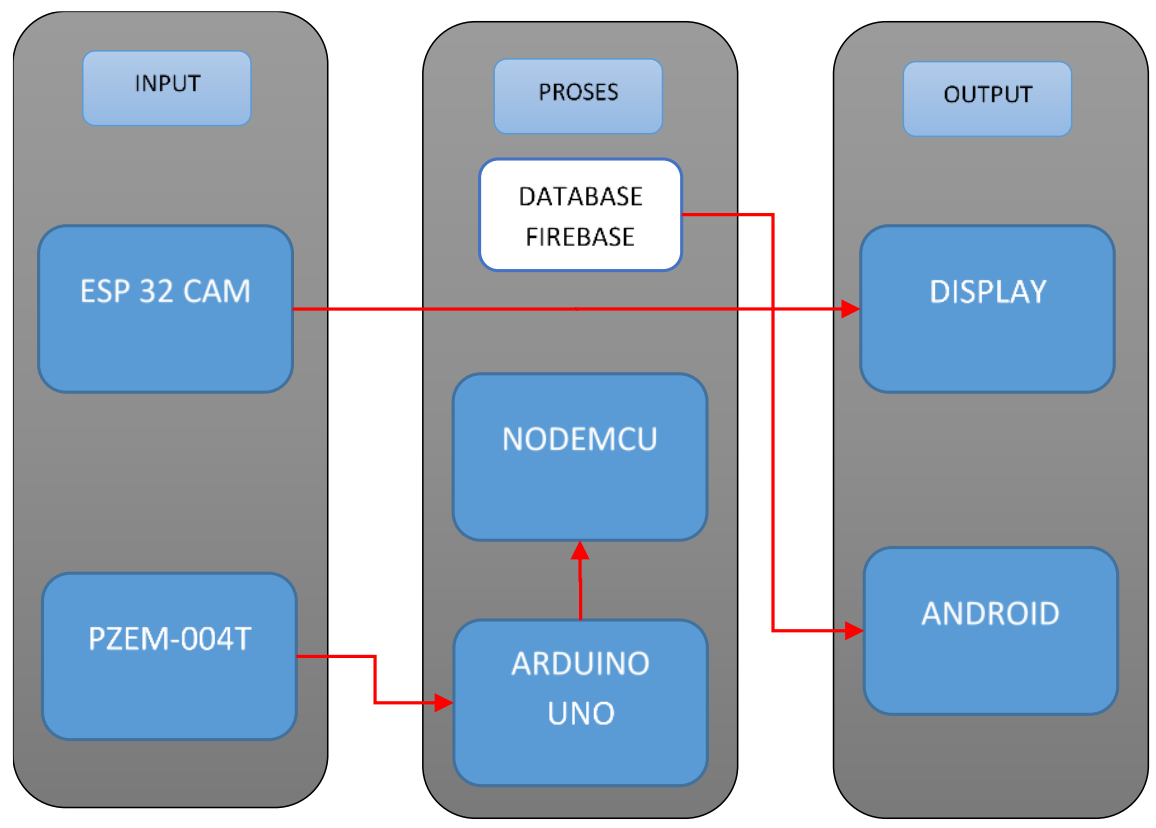

Gambar 5. Blok diagram sistem

\subsubsection{Realisasi Perancangan Perangkat Keras}

Realisasi dari perancangan perangkat lunak tidak terlepas dari perancangan perangkat kerasnya. Perancangan ini mencakup susunan dan hubungan antar komponen dan modul mikrokontroler dan sensor, penempatan modul sensor dan layar penampil. Ditambah lagi dengan keseluruhan rencana sistem yang akan dibuat agar sesuai dengan blok diagramnya.

\section{A. Perancangan Sistem Elektronik Alat}

Gambar 6 merupakan skema perancangan wiring untuk menyambungkan antar komponen dan modul elektronik melalui perantara PCB dan penambahan jack sumber daya eksternal. Rancangan tersebut akan diimplementasikan pada PCB untuk meminimalisir terjadinya error pada perangkat keras akibat efek bad joint atau jumper menggunakan kabel. 


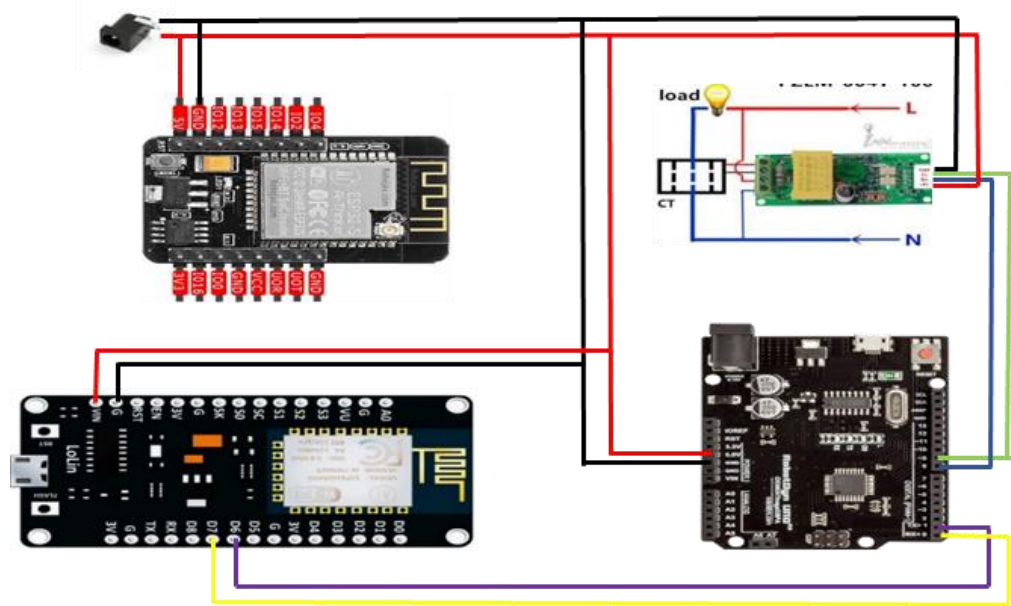

Gambar 6. Skema penyambungan antar komponen dan modul elektronik

\section{B. Perancangan Mekanik Alat}

Gambar 7 merupakan desain PCB yang akan dibuat sebagai media penyambung antar komponen dan modul. Sedangkan gambar 8 merupakan desain realisasi alat yang sudah jadi bila mana sistem sudah siap untuk diterapkan.

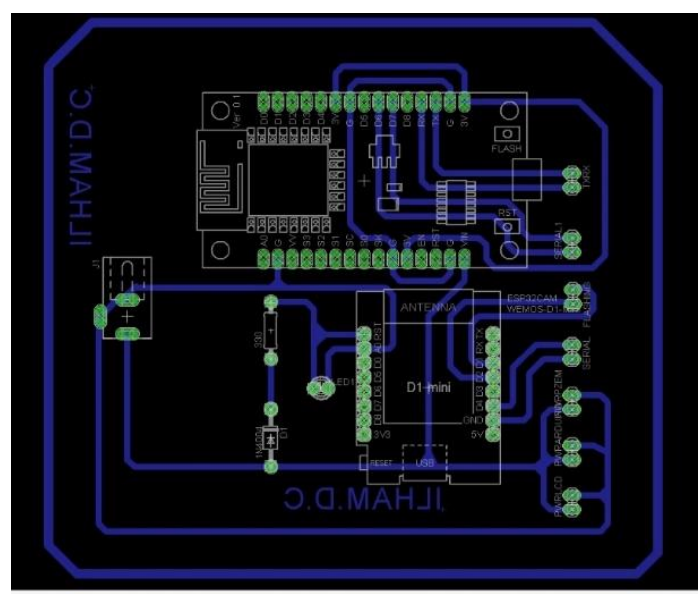

Gambar 7. Desain PCB dan desain realisasi alat

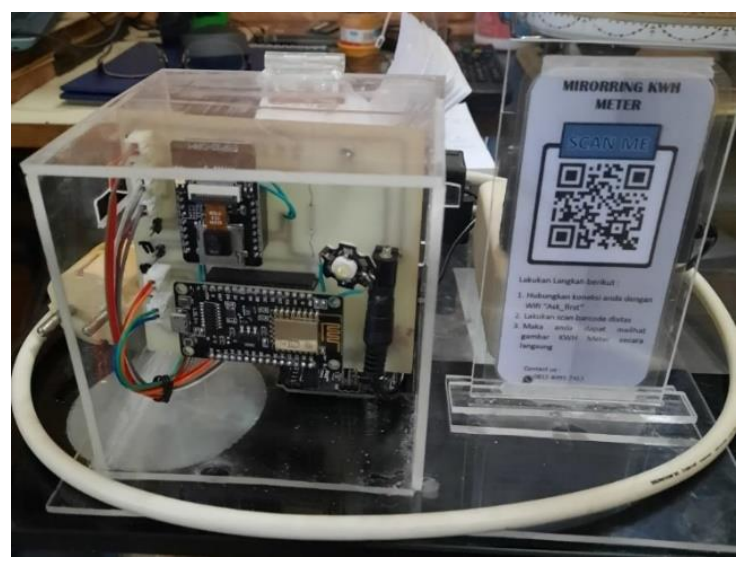

Gambar 8. Desain realisasi alat 


\subsubsection{Perancangan Perangkat Lunak}

Sistem yang akan dibuat salah satunya bertujuan agar memudahkan petugas PLN melihat $\mathrm{kWh}$ meter yang dipasang di rumah. Oleh karena jika petugas PLN tidak dapat mengecek nilai $\mathrm{kWh}$ yang telah digunakan, maka nilainya akan dihitung berdasarkan bulan-bulan sebelumnya. Diharapkan dengan alat ini, petugas PLN dapat melihat nilai kWh yang telah digunakan melalui sistem penampil atau mirroring display dari TFT Display diletakkan di luar rumah. Diagram alir pemrograman pada ESP-32 CAM ditampilkan oleh gambar 9. Gambar tersebut memberitahu bahwa mikrontroller adalah ESP 32 - CAM sebagai otak untuk mirroring display nilai pada $\mathrm{kWh}$ meter secara yang bersifat realtime atau live picture.

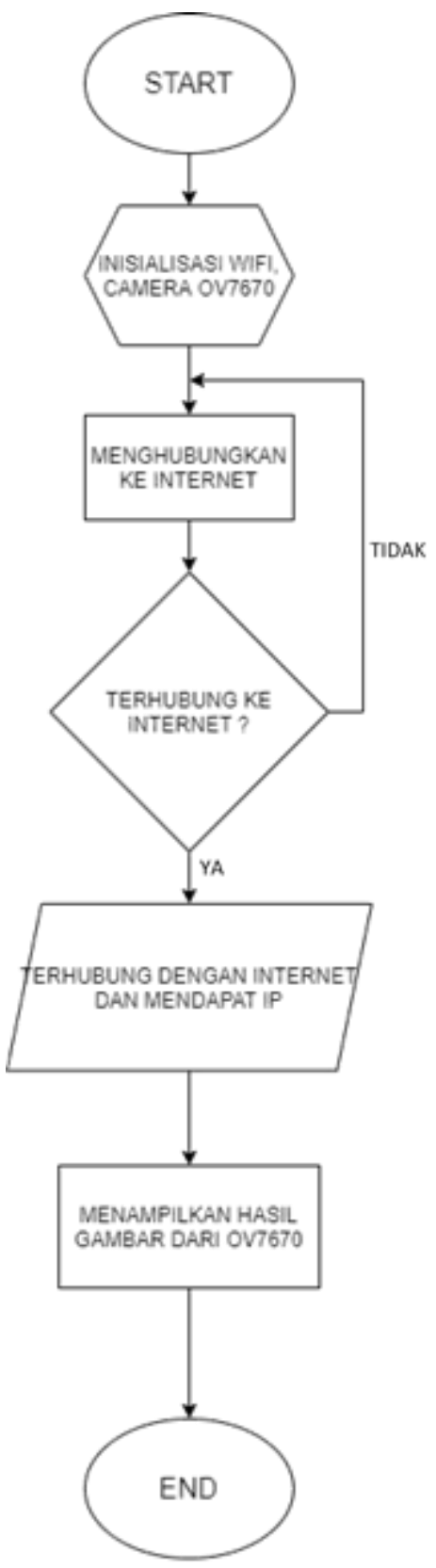

Gambar 9. Diagram alir pemrograman pada ESP-32 CAM

Gambar 9 merupakan diagram alir yang digunakan pada pemrograman mikrokontroller ESP32-CAM khususnya untuk proses pengambilan dan menampilkan gambar hasil capture $\mathrm{kWh}$ meter. Setelah kamera diinisialisasi, kemudian diarahkan untuk terhubung ke internet dan

https://journal.universitasbumigora.ac.id/index.php/bite ISSN: 2685-4066 
ketika sudah tersambung dengan internet, maka akan mendapatkan IP. Setelah mendapatkan IP kamera pada ESP32-CAM kemudian meng-capture gambar dan menampilkannya dengan terlebih dahulu mengakses melalui IP address tertentu.

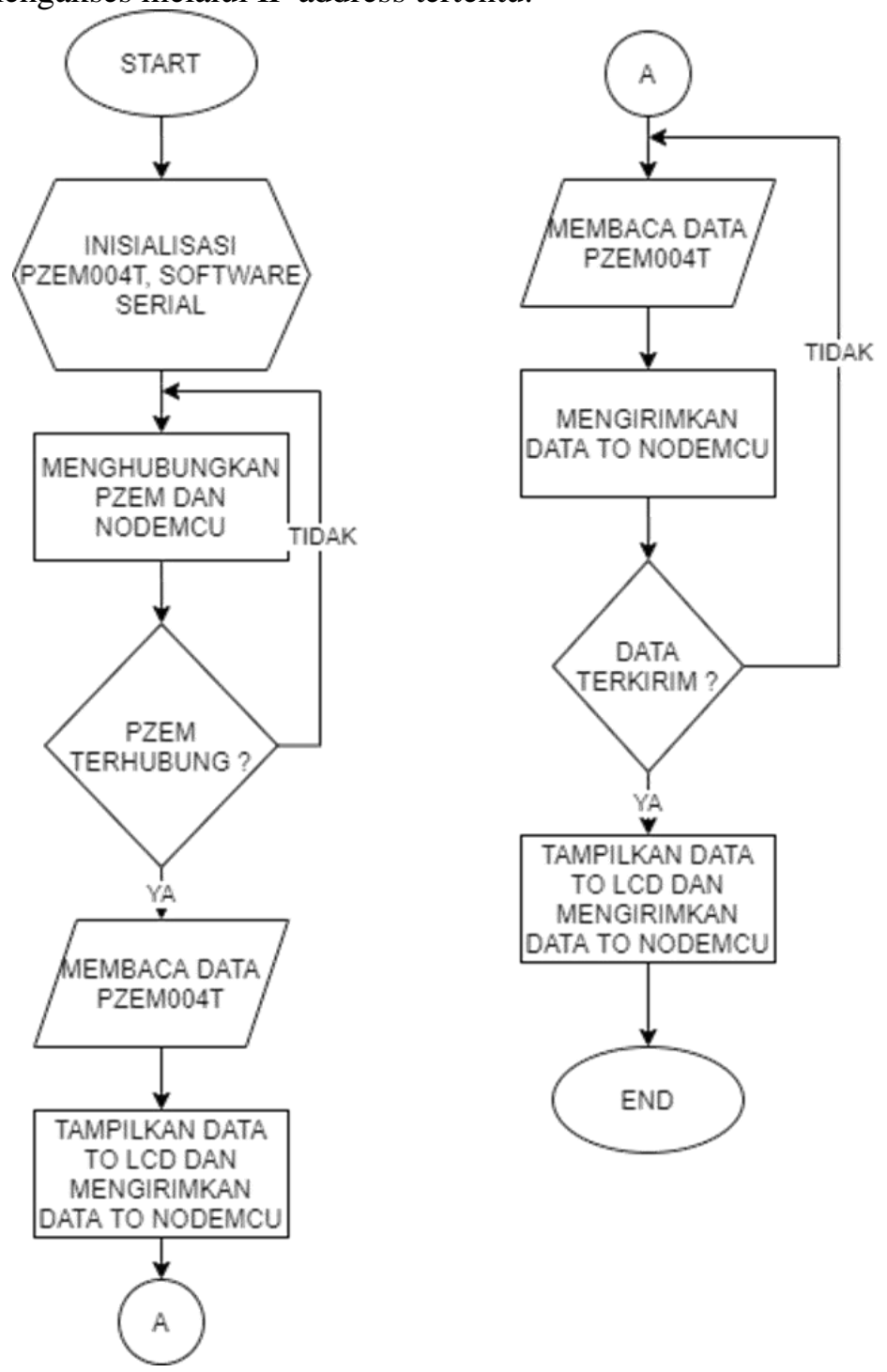

Gambar 10. Diagram alir pada mikrokontroler Arduino UNO

Gambar 10 merupakan diagram alir yang digunakan pada pemrograman mikrokontrollerArduino UNO khususnya untuk proses akuisisi data dari modul sensor PZEM004T dan koneksi dengan mikrokontroler NodeMCU ESP8266 agar bisa terhubung dengan internet. Setelah modul sensor PZEM-004T terhubung dan sudah dapat mengakuisisi data, maka data kemudian ditampilkan melalui LCD TFT dan NodeMCU ESP8266. Data yang ada pada NodeMCU selanjutnya akan diteruskan ke cloud database agar nantinya bisa ditampilkan di aplikasi Android. 


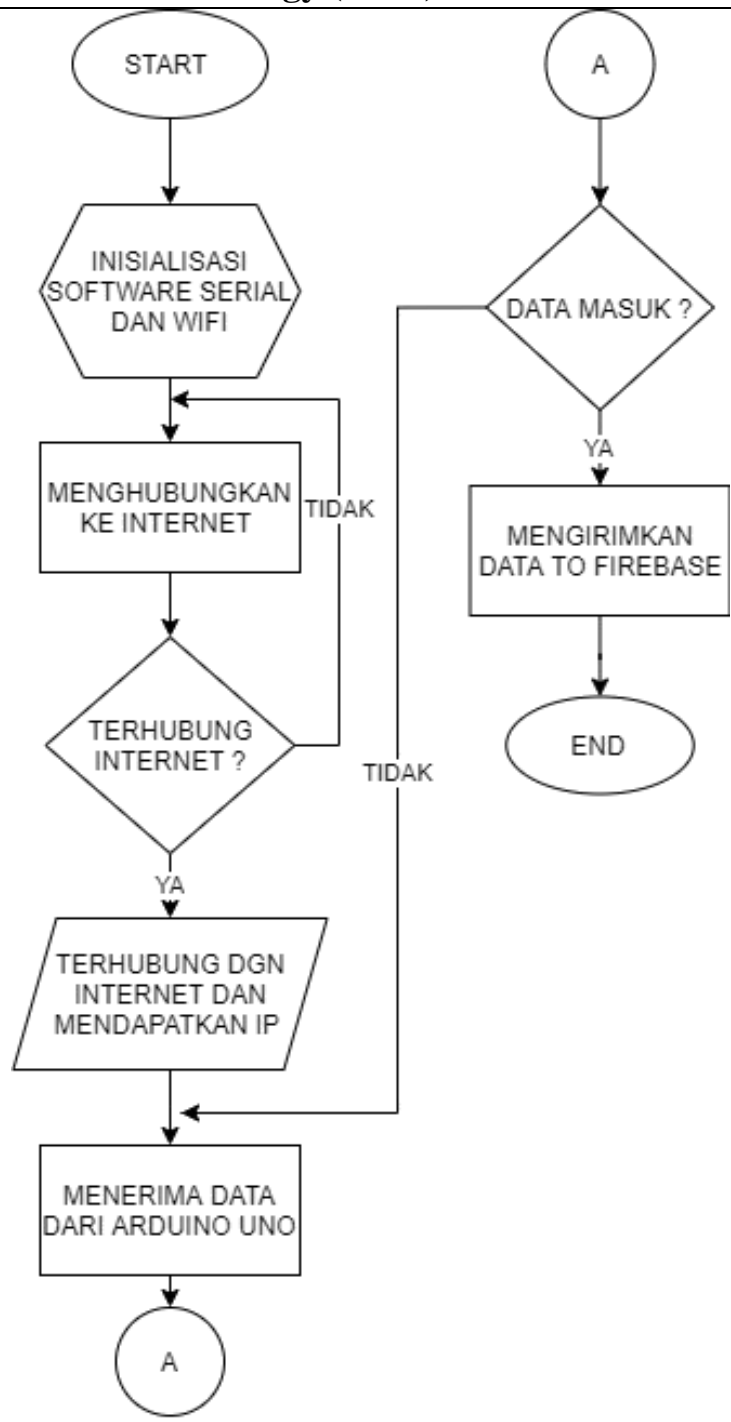

Gambar 11. Diagram alir pada NodeMCU ESP 8266

Gambar 11 merupakan diagram alir yang digunakan pada pemrograman mikrokontroler NodeMCU ESP8266 yang menjabarkan komunikasi dengan cloud Firebase. Data luaran yang didapatkan dari Arduino UNO kemudian diteruskan ke NodeMCU ESP8266 untuk selanjutnya diteruskan ke cloud Firebase dan aplikasi Android. Nantinya, ada dua penampil nilai data, pertama dari layar LCD TFT dan aplikasi Android. Nilai data yang ditampilkan pada aplikasi Android akan memudahkan pengguna khususnya jika tidak berada dalam posisi yang dekat dari alat.

\section{Hasil dan Pembahasan}

Bagian ini mempatkan hasil penelitian berupa pengujian, pengukuran, dan pembahasan berupa analisis dari hasil tersebut.

\subsection{Pengukuran Tegangan dan Arus pada Setrika Listrik}

Tabel 1 merupakan data hasil pengukuran nilai tegangan dan arus yang diterapkan pada setrika listrik menggunakan modul sensor PZEM-004T dan multimeter. Data tersebut dicatat berdasarkan luaran yang ditampilkan oleh LCD TFT pada gambar 12. Hasilnya didapatkan bahwa nilai rata-rata pengukuran tegangan dan arus menggunakan modul sensor PZEM-004T 
masih memiliki selisih nilai yang cukup menjadi perhatian. Rasio perbandingan $\left(\eta_{V}\right)$ nilai tegangan hasil pengukuran menggunakan PZEM-004T dan multimeter adalah:

$$
\eta_{V}=\frac{215,05 \mathrm{~V}}{215,57 \mathrm{~V}} \times 100 \%=99,70 \%
$$

Jika membandingkan dengan nilai tegangan yang seharusnya mengalir pada aliran listrik PLN sebesar 220V, maka hasil pengukuran yang mendekati nilai tersebut adalah menggunakan multimeter. Akan tetapi, aliran listrik tersebut kadangkala bernilai fluktuatif sehingga perlu studi atau riset lanjutan yang khusus membahas nilai tegangan PLN secara langsung. Dengan demikian pada akhirnya bisa mendapatkan data yang sifatnya menguatkan hasil pengukuran sebelumnya.

Hasil pengukuran lainnya adalah nilai arus yang mana rasio perbandingan $\left(\eta_{I}\right)$ nilai arus hasil pengukuran menggunakan PZEM-004T dan multimeter adalah:

$$
\eta_{I}=\frac{1,57 \mathrm{~V}}{1,58 \mathrm{~V}} \times 100 \%=99,36 \%
$$

Hasil pengukuran menggunakan modul sensor PZEM-004T yang digunakan untuk mengukur nilai tegangan dan arus dapat dijadikan informasi seberapa dekat nilai hasil pengukuran menggunakan modul sensor terhadap hasil pengukuran menggunakan multimeter.

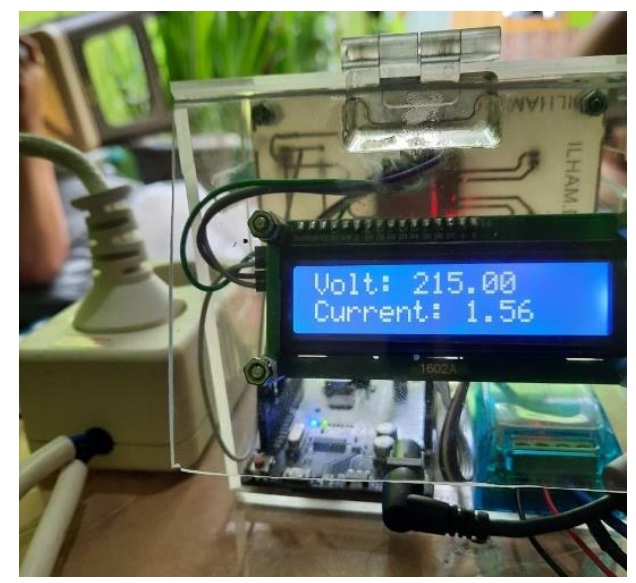

Gambar 12. Tampilan nilai tegangan dan arus pada display LCD

Tabel 1. Data hasil pengukuran tegangan dan arus menggunakan alat yang berbeda.

\begin{tabular}{ccccc}
\hline \multirow{2}{*}{$\begin{array}{c}\text { Pengujian } \\
\text { ke- }\end{array}$} & $\begin{array}{c}\text { Tegangan } \\
\text { dengan } \\
\text { sensor } \\
\text { PZEM-004T } \\
(\mathrm{V})\end{array}$ & $\begin{array}{c}\text { Tegangan } \\
\text { dengan } \\
\text { multimeter } \\
(\mathrm{V})\end{array}$ & $\begin{array}{c}\text { Arus } \\
\text { dengan } \\
\text { sensor } \\
\text { PZEM-004T } \\
(\mathrm{A})\end{array}$ & $\begin{array}{c}\text { Arus dengan } \\
\text { multimeter } \\
(\mathrm{A})\end{array}$ \\
\hline 1 & 214,90 & 215,20 & 1,56 & 1,60 \\
2 & 214,70 & 215,60 & 1,57 & 1,59 \\
3 & 215,00 & 216,20 & 1,57 & 1,57 \\
4 & 215,60 & 215,30 & 1,57 & 1,59 \\
Rata-rata & 215,05 & 215,57 & 1,57 & 1,58 \\
\hline
\end{tabular}

$$
\begin{aligned}
& V A_{P Z E M-004 T}=215,05 \times 1,57=337,63 \mathrm{VA} \\
& V A_{\text {multimeter }}=215,57 \times 1,58=340,60 \mathrm{VA}
\end{aligned}
$$




$$
\eta_{V A}=\frac{337,63 V A}{340,60 V A} \times 100 \%=99,12 \%
$$

Perhitungan tunggal dan gabungan pada kasus perhitungan nilai tegangan, arus dan VA di atas akan memengaruhi hasil akhir dan kesimpulan penelitian.

\subsection{Pengukuran Tegangan dan Arus Diterapkan pada Dua Perangkat}

Selain diterapkan pada setrika, pengujian dalam bentuk pengukuran nilai tegangan dan arus diterapkan pada perangkat tambahan berupa adaptor penurun tegangan $220 \mathrm{~V}$ ke $12 \mathrm{~V}$. Dengan demikian, terdapat dua beban yang mana nilai tegangan dan arusnya diukur langsung. Hasil pengukuran ditampikan pada tabel 2. Dari tabel tersebut sekilas didapati bahwa penambahan beban berdampak pada penurunan nilai tegangan yang terukur. Hal tersebut dapat diyakini terjadi karena semakin besar beban (load) yang ada, maka tegangan dan arus harus menyesuaikannya sehingga terdapat salah satu bagian yang berdampak, yang mana pada kasus ini adalah tegangan. Oleh karena $\mathrm{kWh}$ meter mencatat besarnya energi listrik yang dipakai, maka besarnya nilai tegangan dan arus akan saling mengimbangi satu sama lain.

Tabel 2. Data hasil pengukuran tegangan dan arus menggunakan alat yang berbeda diterapkan pada dua perangkat.

\begin{tabular}{|c|c|c|c|c|}
\hline \multirow[b]{2}{*}{$\begin{array}{l}\text { Pengujian } \\
\text { ke- }\end{array}$} & \multicolumn{4}{|c|}{ Hasil Pengukuran } \\
\hline & $\begin{array}{c}\text { Tegangan } \\
\text { dengan } \\
\text { sensor } \\
\text { PZEM-004T } \\
\text { (V) }\end{array}$ & $\begin{array}{c}\text { Tegangan } \\
\text { dengan } \\
\text { multimeter } \\
\text { (V) }\end{array}$ & $\begin{array}{c}\text { Arus } \\
\text { dengan } \\
\text { sensor } \\
\text { PZEM-004T } \\
\text { (A) }\end{array}$ & $\begin{array}{l}\text { Arus dengan } \\
\text { multimeter } \\
\text { (A) }\end{array}$ \\
\hline 1 & 213,60 & 212,20 & 1,64 & 1,65 \\
\hline 2 & 212,30 & 213,60 & 1,60 & 1,65 \\
\hline 3 & 213,30 & 213,20 & 1,63 & 1,65 \\
\hline 4 & 212,50 & 212,30 & 1,62 & 1,65 \\
\hline Rata-rata & 212,92 & 215,57 & 1,62 & 1,65 \\
\hline \multicolumn{5}{|c|}{$\eta_{V}=\frac{212,92 \mathrm{~V}}{215,57 \mathrm{~V}} \times 100 \%=98,77 \%$} \\
\hline \multicolumn{5}{|c|}{$\eta_{I}=\frac{1,62 V}{1,65 V} \times 100 \%=98,18 \%$} \\
\hline \multicolumn{5}{|c|}{$V A_{P Z E M-004 T}=212,92 \times 1,62=344,93 V A$} \\
\hline \multicolumn{5}{|c|}{$V A_{\text {multimeter }}=215,57 \times 1,65=355,69 \mathrm{VA}$} \\
\hline & $\eta_{V A}=\frac{344}{355}$ & $\frac{3 V A}{9 V A} \times 100$ & $=96,97 \%$ & \\
\hline
\end{tabular}

Jika dilakukan perhitungan nilai VA dari nilai tegangan dan arus rata-rata menggunakan dua alat yang berbeda, maka penambahan alat akan berdampak langsung terhadap nilai VA yang mana nantinya ikut memengaruhi besar/kecilnya tagihan listrik. Akan tetapi, perlu diperhatikan bahwa sensor arus berbasis efek Hall atau magnetic core ini tetap memiliki kelemahan. Kelemahan-kelemahan tersebut antara lain adalah akurasi dan sensitivitas. Akurasi hasil pembacaan nilai arus dapat diketahui dari banyaknya kumparan kompensasi dan lokasi penempatan magnetic core terhadap kawat yang dialiri arus listrik. Kemudian sensitivitas dipengaruhi oleh medan magnet eksternal dan arus listrik yang mengalir di dekat kawat konduktor. 


\subsection{Pengujian Komunikasi Realtime dan Mirroring Display}

Hasil pengujian mirroring display menggunakan ESP 32 CAM terlihat seperti pada gambar 13 . Berdasarkan gambar tersebut, terlihat bahwa nilai angka pada $\mathrm{kWh}$ meter sudah dapat dibaca langsung oleh mata manusia. Cara yang dilakukan untuk mendapatkan gambar adalah dengan menghubungkan camera pada ESP 32 CAM ke IP local address yakni: http://192.168.1.10/. Komunikasi antara Arduino Uno, Node MCU dengan aplikasi Android dapat dilakukan secara realtime. Gambar 13 juga menunjukan bahwa setiap data yang diterima dari PZEM-004T secara realtime pada cloud dan aplikasi Android.

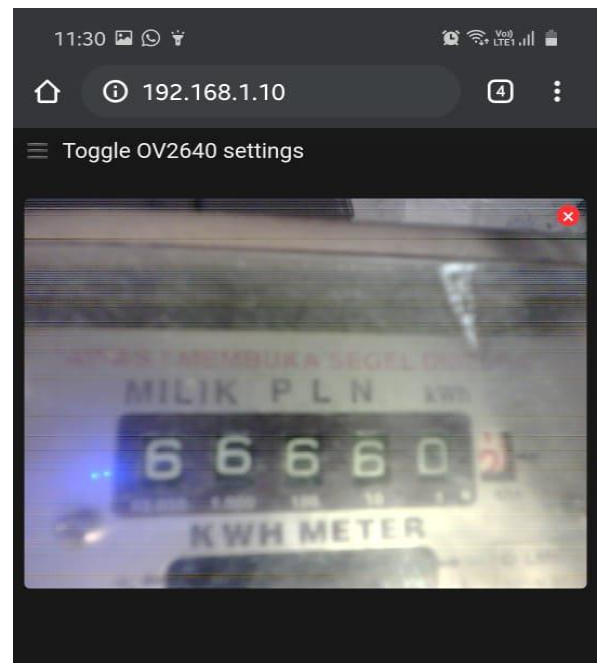

Gambar 13. Hasil mirroring display $\mathrm{kWh}$ meter menggunakan ESP32 CAM

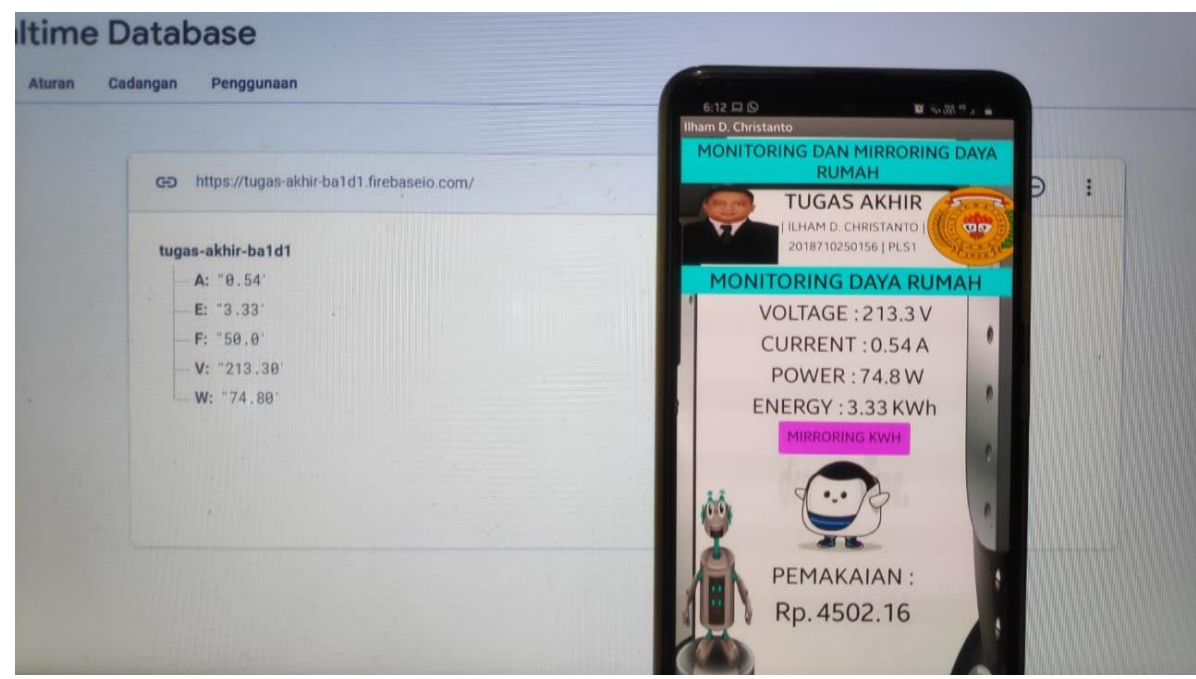

Gambar 14. Tampilan bukti komunikasi antara cloud Firebase dan aplikasi Android

\section{Kesimpulan}

Sistem yang dibuat sudah bisa bekerja sesuai dengan blok diagram dan diagram alir. Rasio nilai VA atau $\eta_{V A}$ dari pengukuran menggunakan alat ukur yang berbeda untuk pengujian satu beban sebesar 99,12\% dan pengujian dua beban sebesar 96,97\%. Didapatkan bahwa semakin besar nilai beban yang diterapkan, akan berdampak pada luaran data seperti arus dan tegangan sehingga memengaruhi besar kecilnya nilai tagihan listrik bulanan. Aplikasi Android dapat digunakan sebagai penampil data kedua setelah layar LCD TFT. Kedepannya, pengembangan aplikasi Android dapat digunakan sebagai kanal tambahan untuk mirroring display. 
[1] A. P. Deni dan R. Mukhaiyar, "Monitoring Daya Listrik Secara Real Time," Vote Teknika, vol. 8, no. 2, pp. 26-34, 2020.

[2] S. Mustafa dan U. Muhammad, "Rancang Bangun Sistem Monitoring Penggunaan Daya Listrik Berbasis Smartphone," Media Elektrik, vol. 17, no. 3, pp. 55-62, 2020.

[3] Risfendra, G. F. Ananda dan S. Alphin, "Internet of Thingspada MonitoringEnergi Listrik Menggunakan Sensor Multi-Parameter Listrik," Motivection Journal of Mechanical Electrical and Industrial Engineering, vol. 3, no. 1, pp. 1-10, 2021.

[4] R. D. Alfian, S. I. Haryudo, U. T. Kartini dan N. Kholis, "Rancang Bangun Alat Monitoring Pemakaian Tarif LIstrik dan Kontrol Daya Listrik pada Rumah Kos Bebasis Internet of Things," Jurnal Teknik Elektro, vol. 10, no. 3, pp. 661-670, 2021.

[5] Andriana, H. Baehaqi dan Zulkarnain, "Sistem KWh Meter Digital Menggunakan Modul PZEM004T,” Jurnal TIARSIE, vol. 16, no. 1, pp. 29-34, 2019.

[6] H. Budi Santoso, S. Prajogo dan S. P. Mursid, "Pengembangan Sistem Pemantauan Konsumsi Energi Rumah Tangga Berbasis Internet of Things (IoT)," ELKOMIKA, vol. 6, no. 3, pp. 357-366, 2018.

[7] M. I. Muchyiddin dan I. Sulistiyowati, "obot Penyemprot Desinfektan Berbasis Internet Of Things (IoT) dan Camera ESP 32," dalam Seminar Nasional \& Call Paper Fakultas Sains dan Teknologi (SENASAINS 1st), Sidoarjo, 2021.

[8] R. Santos, "How to Program / Upload Code to ESP32-CAM AI Thinker (Arduino IDE)," Random Nerd Tutorials, January 2020. [Online]. Available: https://randomnerdtutorials.com/program-uploadcode-esp32-cam/. [Diakses November 2021].

[9] Y. Effendi, "Rancangan Aplikasi Game Edukasi Berbasis MobileMenggunakan App Inventor," Jurnal Intra-Tech, vol. 2, no. 1, pp. 39-48, 2018.

[10] N. Chatterjee, S. Chakraborty, A. Decosta dan D. A. Nath, "Real-time Communication Application Based on Android Using Google Firebase," Intenational Journal of Advance Research in Computer Scince and Management Studies, vol. 6, no. 4, pp. 74-79, 2018. 
